\title{
Complement activation in individuals with previous subclinical Lyme borreliosis and patients with previous Lyme neuroborreliosis
}

\author{
Hanna Carlsson ${ }^{1}$ (D) $\cdot$ Kerstin Sandholm ${ }^{2} \cdot$ Haben Woldu Haddish ${ }^{3} \cdot$ Lars Brudin $^{4} \cdot$ Kristina Nilsson Ekdahl $^{2,5}$. \\ Ivar Tjernberg ${ }^{1}$
}

Received: 30 August 2019 / Accepted: 23 December 2019/ Published online: 31 December 2019

(C) The Author(s) 2019

\begin{abstract}
Lyme borreliosis (LB) is caused by Borrelia burgdorferi and infection may lead to not only a large variety of clinical manifestations but also a subclinical outcome. The aim of the present study was to investigate if there is a constitutional difference in complement activation between individuals with previous subclinical Lyme borreliosis (SB) and patients previously diagnosed with Lyme neuroborreliosis (LNB).

Lepirudin plasma for activation studies was collected from 60 SB individuals and from 22 patients pre-diagnosed with LNB. The plasma was incubated with live Borrelia spirochetes of two strains (complement sensitive B. garinii Lu59 and complement resistant B. afzelii $\mathrm{ACA} 1)$.

Complement factor $\mathrm{C} 3$ was measured in non-activated lepirudin plasma with immune-nephelometry and $\mathrm{C} 3 \mathrm{a}$ and sC5b-9 generated during complement activation were measured by enzyme-linked immunosorbent assay.

We found that the complement sensitive Lu59 induced higher complement activation than the complement resistant ACA1 when measuring activation products $\mathrm{C} 3 \mathrm{a}$ and $\mathrm{sC} 5 \mathrm{~b}-9$ in $\mathrm{SB}$ and LNB patients, $p<0.0001$. No significant difference was found between SB and LNB patients in systemic levels of C3. Furthermore, SB individuals generated a higher activation of $\mathrm{C} 3$ cleavage to $\mathrm{C} 3 \mathrm{a}(\mathrm{C} 3 \mathrm{a} / \mathrm{C} 3$ ratio) than $\mathrm{LNB}$ patients after activation with $\mathrm{ACA} 1, p<0.001$, but no significant differences were found in response to Lu59. In conclusion, Lu59 induced higher complement activation than ACA1 and individuals with previous SB showed increased generation of C3a compared with patients with previous LNB. In our study population, this mechanism could lead to less elimination of spirochetes in LNB patients and thereby be a factor contributing to the clinical outcome.
\end{abstract}

Keywords Complement activation · Subclinical Lyme borreliosis · Lyme neuroborreliosis · Lyme borreliosis · Innate immune system $\cdot \mathrm{C} 3 \mathrm{a}$

Hanna Carlsson

hanna.carlsson2@regionkalmar.se

1 Department of Clinical Chemistry and Transfusion Medicine, Region Kalmar County, Kalmar and Department of Clinical and Experimental Medicine, Linköping University, Linköping, Sweden

2 Centre of Biomaterials Chemistry, Linnaeus University, Kalmar, Sweden

3 Department of Clinical Chemistry and Transfusion Medicine, Region Kalmar County, Kalmar, Sweden

4 Department of Clinical Physiology, Region Kalmar County, Kalmar, Department of Clinical and Experimental Medicine and Department of Medicine and Health Sciences, Linköping University,

Linköping, Sweden

5 Department of Immunology, Genetics and Pathology, Rudbeck Laboratory C5:3, Uppsala University, Uppsala, Sweden

\section{Introduction}

Lyme borreliosis (LB) is the most common tick-borne disease in Europe and North America [1,2]. It is caused by a group of spirochetes called Borrelia burgdorferi sensu lato (B. burgdorferi s.1.). The main disease causing genospecies in Europe are $B$. burgdorferi sensu stricto (B. burgdorferi s.s.), B. afzelii and B. garinii, of which the two latter seem to dominate in ticks and human LB in Sweden and the Åland Islands [3, 4]. Less common disease causing genospecies are $B$. bissettiae, $B$. spielmanii and B. valaisiana [5-8]. Infection by B. burgdorferi s.l. can give rise to various clinical manifestations ranging from the local red skin rash erythema migrans to disseminated infection with symptoms from the nervous system (Lyme neuroborreliosis (LNB)), joints (Lyme arthritis) and skin (Acrodermatitis chronica atrophicans). In 
addition, it seems to be common that B. burgdorferi s.l. infection resolves unnoticed, here called subclinical Lyme borreliosis (SB) [7, 9-12]. Although all genospecies can cause all clinical manifestations, some genospecies are more or less organotropic, e.g. B. afzelii which is most associated with skin manifestations and $B$. garinii with LNB [13].

The innate immune system is the first line of defence when the spirochetes enter the human body. The complement system is a part of the innate immunity and provides a link to the adaptive immune system. It consists of a large number of plasma and membrane-linked proteins that work in a close network and a cascade-linked manner [14-16]. The complement system may be activated through three pathways depending on the recognition molecule. The classical pathway is activated when $\mathrm{C} 1 \mathrm{q}$ binds to antigen bound $\operatorname{IgM}$ or $\operatorname{IgG}$, the lectin pathway is activated when mannan-binding lectin (MBL), collectins or ficolins bind to carbohydrates on the pathogen surface and the alternative pathway is activated when $\mathrm{C} 3 \mathrm{~b}$ or $\mathrm{C} 3\left(\mathrm{H}_{2} \mathrm{O}\right)$ binds to the pathogen surface [14]. Activation of the complement system leads to cleavage of $\mathrm{C} 3$ into $\mathrm{C} 3 \mathrm{a}$ and $\mathrm{C} 3 \mathrm{~b}$ by $\mathrm{C} 3$ convertase followed by cleavage of $\mathrm{C} 5$ into $\mathrm{C} 5 \mathrm{a}$ and $\mathrm{C} 5 \mathrm{~b}$ which initiate the formation of the terminal complement complex C5b-9 (sC5b-9 in soluble form in plasma and membrane attack complex, MAC when inserted in cell membrane). Complement activation products $\mathrm{C} 3 \mathrm{a}$ and sC5b-9 are suitable analytes when studying activation of the complement system since $\mathrm{C} 3 \mathrm{a}$ show activation on the C3-level, relatively high up in the complement cascade and sC5b-9 in the lower part i.e. at C5-level that potentially can give rise to cell lysis. B. burgdorferi s.l. spirochetes can activate the complement system through all three pathways but differ in their ability to overcome attack from the complement system and are classified thereafter. The spirochetes overcome attack, for example, through binding of the regulatory proteins factor $\mathrm{H}$ and factor $\mathrm{H}$ - like protein 1 to complement regulator acquiring surface proteins (CRASPs) on the spirochetal surface and thereby inhibit activation of the complement system [13, 17, 18]. Most B. afzelii strains are complement resistant, B. burgdorferi s.s. are intermediate and most $B$. garinii strains are classified as complement sensitive $[15,19]$.

Although studies show how spirochetes are affected by the complement system, determinants of individual clinical outcome, including subclinical course after B. burgdorferi s.l. infection remains largely unknown with respect to complement activation. Earlier studies indicate that complement activation is important for Borrelia spirochetal phagocytosis and high levels of $\mathrm{C} 1 \mathrm{q}$ and $\mathrm{C} 3$ a have been demonstrated in cerebrospinal fluid (CSF) in patients with $\operatorname{LNB}[15,20]$.

The aim of the present study was to investigate if there is a constitutional difference in complement activation between individuals with previous SB and patients previously diagnosed with LNB.

\section{Material and methods}

\section{Study population and plasma preparation}

The subclinical Lyme borreliosis individuals and Lyme neuroborreliosis patients included in the study were selected as previously described [21]. In brief, in 2012, blood sera were collected from 1126 healthy blood donors together with health inquiries with questions regarding previous history of LB. Sera were screened for multiple Borrelia-specific IgG antibodies and scored according to the manufacturer's instructions (Mikrogen $\mathrm{GmbH}$, Neuried, Germany) [22]. Blood donors who denied previous history of LB and scored a sum $\geq 12$ points in the antibody screen $(n=66)$ were classified as previously subclinically Borrelia seroconverted, SB individuals. Out of these 66 SB individuals, 60 were available for follow-up sampling. Patients with previous LNB included $(n=22)$ fulfilled all inclusion criteria of a previous episode of definite LNB according to the European Federation of Neurological Societies, i.e. pleocytosis in CFS, intrathecal IgM and/or IgG Borrelia antibodies in CFS and clinical symptoms consistent with LNB [21, 23]. Follow-up sampling of SB and sampling of LNB patients were collected simultaneously in the spring (February-April) of 2013 in order to minimize the risk of ongoing or recent Borrelia infection. Blood sera from all study participants were analysed or re-analysed for multiple Borrelia-specific IgG antibodies, spring 2013. Presence of Borrelia-specific IgM antibodies were not analysed due to the low risk of ongoing or recent Borrelia infection. Blood was collected in $11 \mathrm{~mL}$ vacutainer tube (BD Bioscience, Plymouth, Great Britain) prepared with addition of the selective thrombin inhibitor lepirudin (Refludan, Celgene Europe Ltd., Windsor, Great Britain) at a final concentration of $50 \mu \mathrm{g} /$ $\mathrm{mL}$ blood. Lepirudin was chosen as anticoagulant for the activation studies (see below) since it quantitatively inhibits thrombin without affecting complement function [24]. Plasma was collected after centrifugation at $3000 \mathrm{~g}$ for $20 \mathrm{~min}$ at $4{ }^{\circ} \mathrm{C}$ and stored at $-70{ }^{\circ} \mathrm{C}$.

\section{Measurement of complement factor $\mathrm{C} 3$ with $\mathrm{BN}$ ProSpec $^{\circledast}$ System}

Complement factor $\mathrm{C} 3$ was measured in non-activated lepirudin plasma from all of our study participants with an immune-nephelometry method using in vitro diagnostic reagent $\mathrm{N}$ antiserum against human complement factor $\mathrm{C} 3 \mathrm{c}$ and the BN ProSpec ${ }^{\circledR}$ System (Siemens, Erlangen, 
Germany). All analyses were performed according to the manufacturer's instructions.

\section{Borrelia strains and growth conditions}

B. afzelii strain ACA1 isolated from skin biopsy of acrodermatitis chronica atrophicans patients [25] and B. garinii strain Lu59 isolated from human CFS [26] (both strains kindly provided by professor Sven Bergström, Department of Microbiology, University of Umeå, Sweden) were grown in Barbour Stoenner Kelly II (BSKII) medium supplemented with $7 \%$ rabbit serum (Department of Microbiology, University of Umeå, Sweden) at $37{ }^{\circ} \mathrm{C}$ without $\mathrm{CO}_{2}$ until a density of $10^{9} / \mathrm{mL}$.

\section{Complement activation in lepirudin plasma by live Borrelia spirochetes}

The spirochetes were washed in phosphate buffered saline (PBS) supplemented with $0.9 \mathrm{mM} \mathrm{Ca}^{2+}$ (Sigma-Aldrich, Darmstadt, Germany) by centrifugation at $2500 \mathrm{~g}$ for 10 min and then re-suspended in PBS with $\mathrm{Ca}^{2+}$ to a final concentration of $1 \times 10^{10} / \mathrm{mL}$. In $2 \mathrm{~mL}$ polypropylene tubes, $50 \mu \mathrm{L}$ re-suspended spirochetes of $B$. afzelii ACA1 and $B$. garinii Lu59 were incubated with $450 \mu \mathrm{L}$ lepirudin plasma from each study participant for $60 \mathrm{~min}$ at $37^{\circ} \mathrm{C}$. The activation was stopped by addition of ethylenediaminetetraacetic acid (EDTA)(Sigma) at a final concentration of $10 \mathrm{mM}$, centrifuged at $4500 \mathrm{~g}$ for $5 \mathrm{~min}$ and $400 \mu \mathrm{L}$ of plasma were collected and stored at $-80^{\circ} \mathrm{C}$ until further analyses. As negative/background control, lepirudin plasma without addition of spirochetes was run in parallel. All samples were run in duplicate, see Fig. 1.

\section{Determination of C3a and sC5b-9 by enzyme linked immunosorbent analysis}

Complement activations products $\mathrm{C} 3 \mathrm{a}$ and $\mathrm{sC} 5 \mathrm{~b}-9$ were measured with sandwich enzyme linked immunosorbent analysis (ELISA) as previously described [27, 28] using mAbs.

4SD17.3 and anti-Hu-C9 mab aEII (Bioporto Diagnostics A/S, Hellerup, Denmark) for capture and polyclonal biotinylated rabbit anti-human $\mathrm{C} 3 \mathrm{a}$ and polyclonal biotinylated sheep anti-human-C5 antibody BP373 (Acris, Herford, Germany) for detection. Zymosan activated serum was used as standard and zymosan activated pooled serum from blood donors were used as control [27]. The inter-assay coefficients of variation (CV) for the analyses were the following: $\mathrm{C} 3 \mathrm{a}, 19.5 \%$ and sC5b-9, 13\%. Analyses of the complement activation products $\mathrm{C} 3 \mathrm{a}$ and $\mathrm{sC} 5 \mathrm{~b}-9$ were run in duplicates (Fig. 1) and in parallel for each study participant and both SB and LNB patients were represented on all microtiter plates. One of the samples from one of the subclinical individuals failed to be analysed for sC5b-9 and was therefore not included in further statistical analysis.

\section{Statistics}

For the Borrelia strains influence on the complement activation, data are presented as activation compared with plasma control run in parallel without addition of spirochetes (x-fold). For statistical analyses of Borrelia-specific complement activation between our study groups, the ratio between activated plasma concentration of $\mathrm{C} 3 \mathrm{a}$ minus plasma control and intact C3 was used and for sC5b-9, Borrelia-specific activation concentration minus plasma control was used. Mann-Whitney's non-parametric $U$ test was used for non-parametrical comparisons between groups. Since there were age and sex

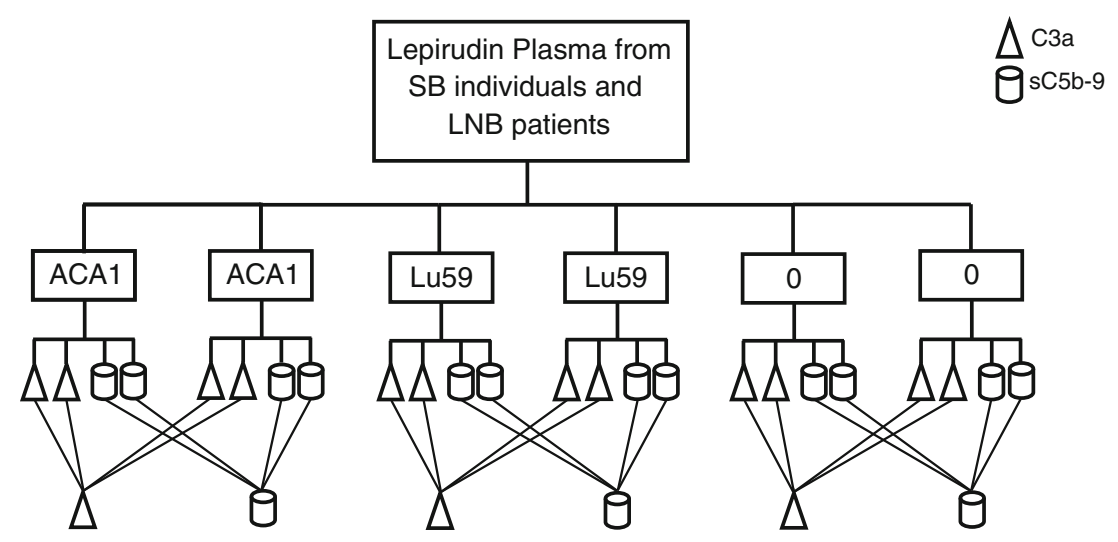

Fig. 1 Flow-chart of complement activation in lepirudin plasma with live Borrelia spirochetes and following determination of C3a and sC5b-9 with enzyme linked immunosorbent assay. We performed our complement activation experiments in duplicates. When determining $\mathrm{C} 3 \mathrm{a}$ and $\mathrm{sC} 5 \mathrm{~b}-$ 9 , we ran each activation duplicate in duplicates. The average concentration of each complement marker minus the background were thereafter used in the statistical analysis. SB, subclinical individuals; LNB, Lyme neuroborreliosis patients; 0, negative/background control; lepirudin plasma without addition of spirochetes 
differences between the two study groups, a multiple logistic regression was also made in order to adjust for this. In the logistic model, the regression coefficients $\left(b_{i}\right)$ are calculated iteratively using the non-linear equation: $y=\exp .\left(b_{0}+b_{1} x_{1}+\right.$ $\left.b_{2} x_{2} \ldots b_{n} x_{n}\right) /\left\{1-\left(\exp \left(b_{0}+b_{1} x_{1}+b_{2} x_{2} \ldots b_{n} x_{n}\right\}\right.\right.$, where $y$ is the binary dependent variable (SB or LNB), and $x_{i}$ are the $n$ independent variables (including sex and age). The $\mathrm{C} 3 \mathrm{a} / \mathrm{C} 3$ ratio (ACA1) was lognormally distributed, and therefore, the natural logarithm was used. Adjusting for Borrelia-specific antibodies was not possible due to its distribution between groups (Table 1). Statistical analyses of data were performed using GraphPad Prism version 8 (GraphPad Software Inc., La Jolla, CA, USA) and Statistica version 13 (Dell inc., Tulsa, OK, USA). A $p$ value $<0.05$ was considered to be significant.

\section{Results}

Subclinical Lyme borreliosis individuals and Lyme neuroborreliosis patients.

We included $60 \mathrm{SB}$ individuals in our study. Out of these, 48 were men and 12 women and they had a median age of 51 years (range 20-68 years). All 60 of the included SB individuals were found seropositive for anti-Borrelia IgG

Table 1 Study participant characteristics and complement marker results

\begin{tabular}{|c|c|c|c|}
\hline Variable & SB & LNB & $\begin{array}{l}\text { Difference } \\
p \text { value }\end{array}$ \\
\hline$N$ & 60 & 22 & \\
\hline \multicolumn{4}{|l|}{ Age, years } \\
\hline Median (range) & $51(20-68)$ & $66(18-82)$ & $<0.001$ \\
\hline \multicolumn{4}{|l|}{ Sex } \\
\hline Female & $12(20)$ & $11(50)$ & \\
\hline Male & $48(80)$ & $11(50)$ & 0.012 \\
\hline \multicolumn{4}{|c|}{ Seropositive for anti-Borrelia IgG antibodies ${ }^{a}$} \\
\hline No & $0(0.0)$ & $15(68.2)$ & \\
\hline Yes & $60(100.0)$ & $7(31.8)$ & - \\
\hline \multicolumn{4}{|l|}{$\mathrm{C} 3, \mathrm{~g} / \mathrm{L}$} \\
\hline Median (range) & $1.02(0.65-2.98)$ & $1.05(0.72-1.54)$ & 0.743 \\
\hline \multicolumn{4}{|c|}{$\mathrm{C} 3 \mathrm{a} / \mathrm{C} 3$ ratio $\times 1000(\mathrm{ACA} 1)$} \\
\hline Median (range) & $5.2(0.3-25.6)$ & $2.2(0.5-11.6)$ & $<0.001$ \\
\hline \multicolumn{4}{|c|}{$\mathrm{C} 3 \mathrm{a} / \mathrm{C} 3$ ratio $\times 1000(\mathrm{Lu} 59)$} \\
\hline Median (range) & $9.2(3.3-39.5)$ & $7.4(3.8-29.5)$ & 0.157 \\
\hline \multicolumn{4}{|l|}{ sC5b-9 (ACA1), mg/L } \\
\hline Median (range) & $8.8(0.5-31.2)$ & $6.4(0.8-17.8)$ & 0.118 \\
\hline \multicolumn{4}{|l|}{ sC5b-9 (Lu59), mg/L } \\
\hline Median (range) & $25.1(7.3-55.9)$ & $26.3(10.7-49.0)$ & 0.870 \\
\hline
\end{tabular}

${ }^{a}$ Seropositive for anti-Borrelia antibodies according to the manufacturer's (Mikrogen $\mathrm{GmbH}$, Neuried, Germany) scoring system at the time of inclusion in this study. $N$, number of cases; $S B$, subclinical individuals; $L N B$, Lyme neuroborreliosis antibodies according to the manufacturer's scoring system at the time of follow-up sampling. The included LNB patients $(n=22)$ consisted of 11 men and 11 women. Their median age at inclusion were 66 years (range 18-82 years). LNB patients were diagnosed between February 1st of 2008 and May 31st of 2012, and a median of 3.1 years (range 0.7-5.1 years) had passed between LNB diagnosis and inclusion in this study. At the time of diagnosis, all LNB patients exhibited intrathecal anti-Borrelia antibodies, and in peripheral blood, all but one LNB patient ( $n=21 / 22$ ) were seropositive for anti-Borrelia IgG antibodies. At the time of inclusion in this study, seven out of the $22(32 \%)$ LNB patients were found seropositive for anti-Borrelia IgG antibodies according to the manufacturer's scoring system. Antigen reactivities of SB individuals and LNB patients seropositive for anti-Borrelia IgG antibodies at follow-up sampling and inclusion, respectively, are presented in Table 2 . The LNB patients included were significantly older than the SB individuals, $p<0.001$ and the SB group consisted of significantly more men than the LNB patients, $p=0.012$.

\section{Complement factor C3 in non-activated lepirudin plasma}

We measured the concentration of complement factor $\mathrm{C} 3$ with nephelometry in non-activated lepirudin plasma from $\mathrm{SB}(n=$ $60)$ and LNB patients $(n=22)$. We found no significant differences between SB and LNB patients in constitutionally expressed $\mathrm{C} 3$ (Fig. 2). The concentration of $\mathrm{C} 3$ in $\mathrm{SB}$ showed a median of $1.02 \mathrm{~g} / \mathrm{L}$ (range $0.65-2.98 \mathrm{~g} / \mathrm{L}$ ) and in LNB patients $1.05 \mathrm{~g} / \mathrm{L}$ (range $0.72-1.54 \mathrm{~g} / \mathrm{L}$ ), $p=0.743$. The reference interval of the analysis is $0.9-1.8 \mathrm{~g} / \mathrm{L}$ [29].

\section{Complement activation in lepirudin plasma activated with Borrelia strain Lu59 and ACA1}

The complement sensitive Borrelia strain Lu59 induced higher complement activation than the complement resistant Borrelia strain ACA1 when measuring activation products $\mathrm{C} 3 \mathrm{a}$ and $\mathrm{sC} 5 \mathrm{~b}-9$ in lepirudin plasma from SB and LNB patients, $p<0.0001$ (Fig. 3).

\section{Complement activation in subclinical individuals and Lyme neuroborreliosis patients}

We found that SB individuals generated a higher activation of $\mathrm{C} 3$ cleavage to $\mathrm{C} 3 \mathrm{a}(\mathrm{C} 3 \mathrm{a} / \mathrm{C} 3$ ratio) than $\mathrm{LNB}$ patients after activation with ACA1, $p<0.001$ (Fig. 4). The significant difference in activation between SB and LNB remained after adjusting for age and sex using logistic regression (OR (95\% $\mathrm{CL})=0.39(0.19-0.77) ; p=0.007)$ and regardless of the presence or absence of Borrelia-specific serum antibodies, $p=$ 0.03 and $p=0.006$, respectively (Fig. 5). In contrast, no significant difference was found between SB and LNB patients in 
Table 2 Summary of antigen reactivities of subclinical Lyme borreliosis individuals and Lyme neuroborreliosis patients seropositive for anti-Borrelia IgG antibodies at follow-up sampling and inclusion, respectively

\begin{tabular}{|c|c|c|c|c|c|c|c|c|c|c|c|c|c|}
\hline \multirow[t]{2}{*}{ Group } & \multicolumn{13}{|c|}{ Anti-Borrelia IgG antibodies } \\
\hline & $\begin{array}{l}\text { p100 } \\
\text { B.afz }\end{array}$ & VlsE & $\begin{array}{l}\text { p58 } \\
\text { B.gar }\end{array}$ & $\begin{array}{l}\text { p39 } \\
\text { B.afz. }\end{array}$ & $\begin{array}{l}\text { OspA } \\
\text { B.afz }\end{array}$ & $\begin{array}{l}\text { OspC } \\
\text { B.ss. }\end{array}$ & $\begin{array}{l}\text { OspC } \\
\text { B.afz. }\end{array}$ & $\begin{array}{l}\text { OspC } \\
\text { B.gar. }\end{array}$ & $\begin{array}{l}\mathrm{p} 18 \\
\text { B.ss. }\end{array}$ & $\begin{array}{l}\text { p18 } \\
\text { B.afz. }\end{array}$ & $\begin{array}{l}\mathrm{p} 18 \\
\text { B.bav. }\end{array}$ & $\begin{array}{l}\mathrm{p} 18 \\
\text { B.gar. }\end{array}$ & $\begin{array}{l}\text { p18 } \\
\text { B.sp. }\end{array}$ \\
\hline \multicolumn{14}{|l|}{$\mathrm{SB}(n=60)$} \\
\hline $\begin{array}{l}n \text { seropositive } \\
(\%)\end{array}$ & $47(78)$ & $60(100)$ & $45(75)$ & $20(33)$ & $1(1.6)$ & $3(5)$ & $2(3)$ & $5(8)$ & $1(1.6)$ & $42(70)$ & $6(10)$ & $3(5)$ & $1(1.6)$ \\
\hline \multicolumn{14}{|l|}{$\operatorname{LNB}(n=22)$} \\
\hline $\begin{array}{l}n \text { seropositive } \\
(\%)\end{array}$ & $5(23)$ & $12(55)$ & $7(32)$ & $0(0)$ & $0(0)$ & $2(9)$ & $1(4.5)$ & $3(14)$ & $0(0)$ & $1(4.5)$ & $1(4.5)$ & $2(9)$ & $0(0)$ \\
\hline
\end{tabular}

B.afz, Borrelia afzelii; B.bav, Borrelia bavariensis; B.gar, Borrelia garinii; B.ss, Borrelia sensu stricto; $L N B$, Lyme neuroborreliosis;; $n$, number of study participants; Osp, outer surface protein; $p 18$, Decorin binding protein; $p 39$, Borrelial membrane protein A; $p 58$, oligopeptide permease; $p 100$, uncharacterised Borrelia specific antigen; $S B$, subclinical Lyme borreliosis; VlsE, surface lipoprotein E [22]

$\mathrm{C} 3 \mathrm{a} / \mathrm{C} 3$ ratio in response to Lu59, $p=0.157$. Neither did we find any significant differences between SB and LNB patients in generated $\mathrm{sC} 5 \mathrm{~b}-9$ concentration after activation of lepirudin plasma with Borrelia strain ACA1 or Lu59, $p=0.118$ and $p=$ 0.870 , respectively. Study participant characteristics and complement marker results are shown in Table 1.

\section{Discussion}

In the present study, we investigated complement activation in lepirudin plasma from SB individuals and LNB patients in response to ex vivo stimulation with $B$. afzelii strain ACA1 and $B$. garinii strain Lu59. We measured complement activation products $\mathrm{C} 3 \mathrm{a}$ and $\mathrm{sC} 5 \mathrm{~b}-9$ using ELISA. The main finding of the study was that SB individuals induced higher

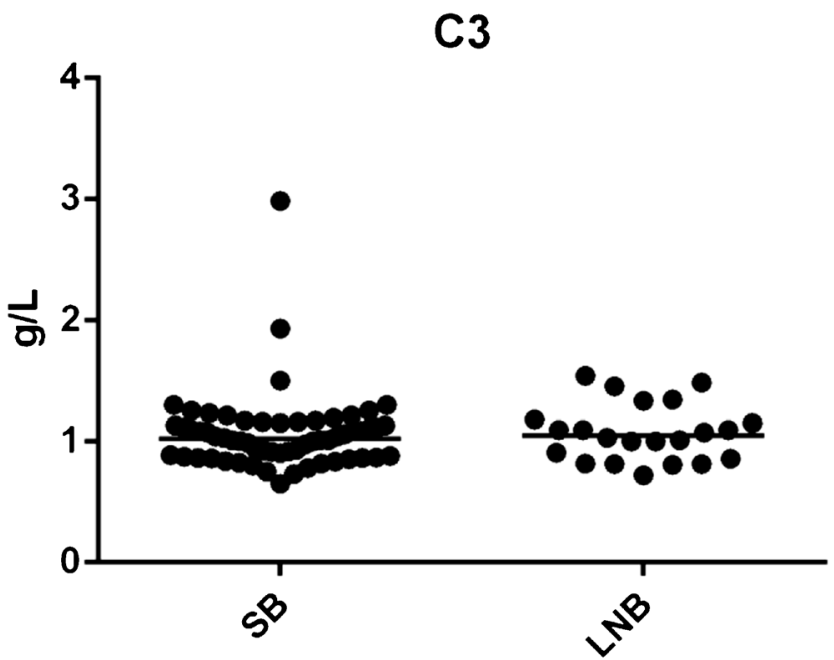

Fig. 2 Complement factor $\mathrm{C} 3$ in non-activated lepirudin plasma. No significant differences were observed in constitutionally expressed complement factor $\mathrm{C} 3$ between SB and LNB patients, $p=0.743$. SB; subclinical individuals, LNB; Lyme neuroborreliosis patients complement activation through cleavage of $\mathrm{C} 3$ to $\mathrm{C} 3 \mathrm{a}$ than LNB patients in response to $B$. afzelii.

Interestingly, we observed a significant difference in complement activation only between SB and LNB patients in response to $B$. afzelii but not in response to $B$. garinii, even though $B$. garinii is the strain mostly associated with LNB [13]. How the infecting Borrelia strain affect the clinical outcome and to what extent is complex and have no perspicuous explanations. In our study population, we do not know what strain of Borrelia the subjects have been exposed to in vivo. We suppose that the SB individuals most likely have been exposed to $B$. afzelii, but we cannot exclude the possibility of that the SB individuals would develop LNB if exposed to B. garinii. To complicate the matter even further, LNB can be caused by $B$. afzelii, and if that is the case in our LNB patients, this could explain why they develop the disseminated form of borreliosis due to unfavourable activation of the complement system. Different ways for Borrelia spirochetes to overcome attack from the complement system via different pathways have been studied extensively as discussed e.g. in Kraiczy (2016) and references therein [18]. CRASPs in the B. afzelii cell membrane have the ability to binding the regulatory proteins factor $\mathrm{H}$ and factor $\mathrm{H}$-like protein 1 (FHL-1) which control activation of the alternative pathway. Furthermore, different Osp-E related proteins (Erps) can bind the factor H-related proteins (FHRs) FHR-1, FHR-2 and FHR-5 which may be accompanied with a displacement of factor $\mathrm{H}$ and subsequent complement mediated lysis [18].

The immune system is very complex, and the complement system is only a part of the innate immune response against bacterial infections and is also closely linked to downstream activation of the adaptive immune system through e.g. the anaphylatoxins $\mathrm{C} 3 \mathrm{a}$ and $\mathrm{C} 5 \mathrm{a}$ and their chemotactic ability to recruit adaptive immune cells. In contrast to our findings in the present study, where the complement activity seems to differ in SB and LNB in response to B. afzelii, in our previous study, we 


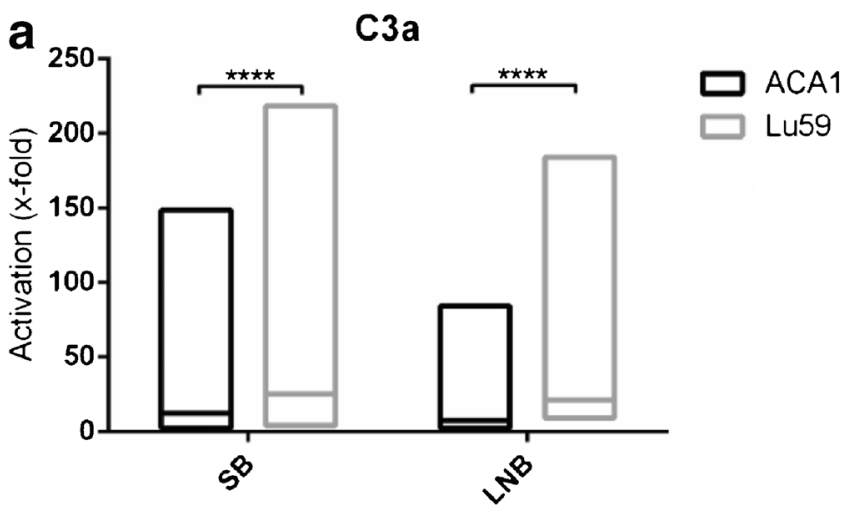

Fig. 3 Complement activation in vitro in lepirudin plasma activated with Borrelia strain ACA1 and Lu59 from subclinical Lyme borreliosis individuals and patients with previous Lyme neuroborreliosis. Complement activation in lepirudin plasma activated with Borrelia strain ACA1 and Lu59 were assessed by measurement of generated C3a and sC5b-9 with ELISA. Sample data were normalized against

found differences between SB and LNB in the adaptive immune responses when activating with $B$. garinii [21]. This might indicate that the different Borrelia strains are affected differently by various parts of the immune system and the diverse responses might contribute to the pathogenesis of Borrelia infection. Why only B. afzelii strain ACA1 induced higher complement activation through generation of $\mathrm{C} 3 \mathrm{a}$ and how this might be associated with clinical outcome needs to be further explored.

The significant difference between SB and LNB patients in $\mathrm{C} 3 \mathrm{a} / \mathrm{C} 3$ ratio remained regardless of presence of Borrelia-specific antibodies. This suggests that the presence of Borreliaspecific antibodies may not be required for complement activation in the regard of clinical outcome after Borrelia exposure and that more than one complement activation pathway may be involved in the immune response against Borrelia infection.

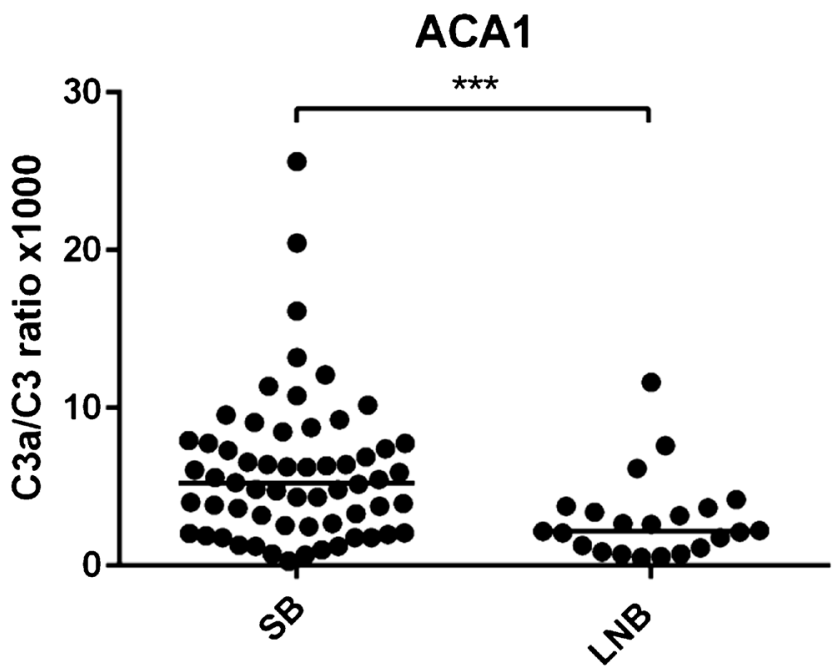

Fig. 4 Complement activation in vitro monitored as the ratio of $\mathrm{C} 3$ a to intact $\mathrm{C} 3$ in lepirudin plasma from subclinical Lyme borreliosis individuals and patients with previous Lyme neuroborreliosis. SB generated a higher $\mathrm{C} 3 \mathrm{a} / \mathrm{C} 3$ ratio in lepirudin plasma after activation with Borrelia strain ACA1, *** $p<0.001$. SB, subclinical individuals; LNB; Lyme neuroborreliosis

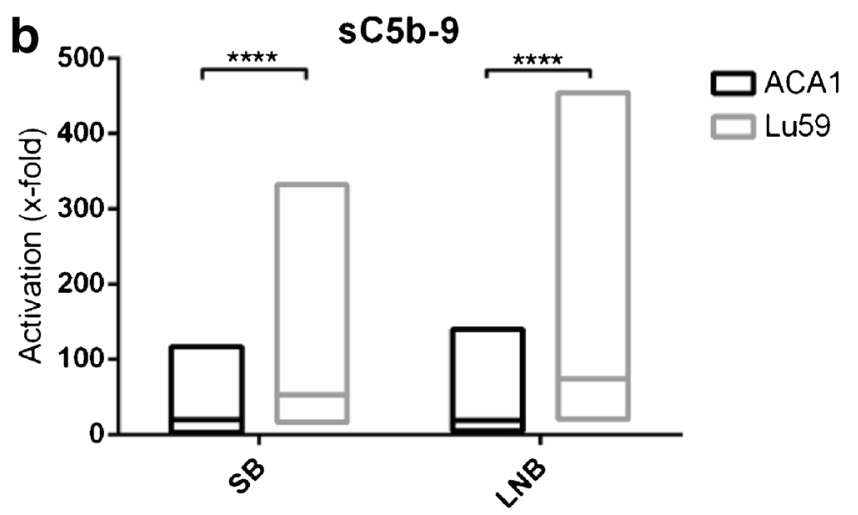

lepirudin plasma run in parallel, but without addition of spirochetes in the activation step. Boxes represent minimum and maximum with line at median. a Generated C3a from SB $(n=60)$ and LNB patients $(n=22)$. b Generated sC5b-9 from SB $(n=59)$ and LNB patients $(n=22)$. SB, Subclinical individuals; LNB, Lyme neuroborreliosis. $* * * p<0.0001$

Contrary to C3a, levels of sC5b-9 did not differ between SB individuals and LNB patients regardless of activation with either ACA1 or Lu59. This might indicate that the terminal complement pathway and lysis of the spirochetes is not affected and remains similar in our study populations. It also indicates that other mechanisms are involved in the early immune response to Borrelia spirochete eradication and that other parts of the innate immune system such as phagocytosis by

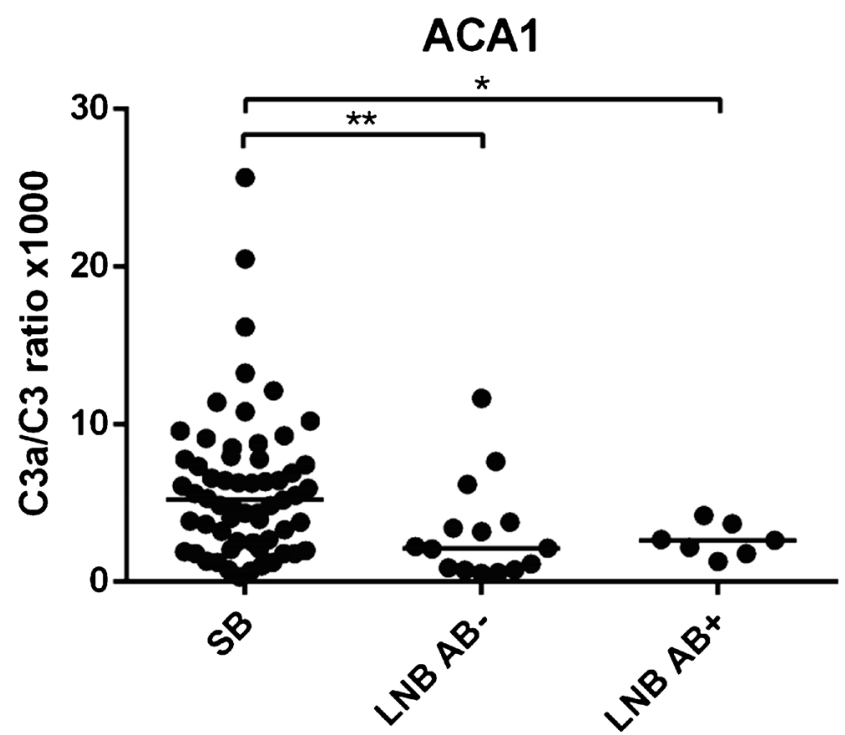

Fig. 5 Complement activation in vitro monitored as the ratio of $\mathrm{C} 3 \mathrm{a}$ to intact $\mathrm{C} 3$ in lepirudin plasma from subclinical Lyme borreliosis individuals and patients with previous Lyme neuroborreliosis with or without concomitant Borrelia-specific antibodies in serum. SB generated higher $\mathrm{C} 3 \mathrm{a} / \mathrm{C} 3$ ratio after activation with Borrelia strain ACA1 than LNB patients with Borrelia-specific serum antibodies and without Borrelia-specific serum antibodies at the time of activation, $* p=0.03$ and $* * p=0.006$ respectively. $\mathrm{SB}$, subclinical individuals; LNB AB-, Lyme neuroborreliosis patients without Borrelia-specific serum antibodies at the time of study inclusion; LNB AB+, Lyme neuroborreliosis patients with Borrelia-specific serum antibodies at the time of study inclusion 
macrophages, recruitment of immune cells and activation of the adaptive immune system influence the various clinical outcomes after Borrelia exposure.

Sex and age seem to play a role in clinical outcome after Borrelia exposure. Sex and age differences have previously been linked to seroprevalence $[4,30,31]$, and male sex and lower age seem more common in subclinical outcome after Borrelia exposure [21]. The complement system of the innate as well as the adaptive immune system differs between the sexes and alters with age [32, 33]. Regardless of the potential effects of such differences in our study, there seems to be an independent difference between the SB individuals and LNB patients supported by the demonstrated complement activation difference after sex and age adjustment.

Previous studies together with our data confirm that the complement sensitive $B$. garinii Lu59 induce higher complement activation than the complement resistant $B$. afzelii ACA1 [13, 15, 17-19].

There are some limitations in our present study. As we in a previous study described, there is a potential risk of selection bias in our group of SB individuals due to recall bias, i.e. blood donors may have forgotten an LB episode, but this should be compensated by the higher cut-off for Borrelia antibodies [21]. By using the presence of anti-Borrelia antibodies as an inclusion criterion for the SB individuals, we could not include individuals that have had a previous subclinical borreliosis after Borrelia exposure without seroconversion. One should also keep in mind that seroconversion is not always observed in symptomatic LB either [34]. Our findings need to be confirmed with similar study populations and it would be interesting to include and follow a group of patients with erythema migrans with known exposure time and infecting Borrelia strain. Furthermore, it would be valuable to include additional (sub)species of Borrelia strains in order to confirm these present results. Presence or absence of antiBorrelia IgM as well as IgG antibodies involvement in complement activation and the link to clinical outcome after Borrelia exposure also needs to be further explored.

In conclusion, the complement sensitive Borrelia garinii strain Lu59 induced higher complement activation than the complement resistant Borrelia afzelii strain ACA1. Individuals with previous SB induced higher complement activation through generation of $\mathrm{C} 3$ a than patients with previous LNB. In our study population, this mechanism could lead to less elimination of spirochetes in LNB patients and thereby be a factor contributing to the clinical outcome.

Acknowledgements We would like to thank the personnel at the blood donor centre in Region Kalmar County for their assistance in collecting the blood donor sera. We also like to thank professor Sven Bergström and laboratory assistant Ingela Nilsson, Department of Microbiology, Umeå University, Sweden for kindly supplying the Borrelia strains and BSK II medium. We would also like to thank PhD student Malin Lager, Laboratory Medicine, Region Jönköping County, Sweden, for performing the recomBead Borrelia IgG analyses and $\mathrm{PhD}$ Linda Fryland, Division of Clinical Immunology, Linköping University, Linköping, Sweden for help with performing the complement activation in lepirudin plasma by live Borrelia spirochetes.

Funding information Open access funding provided by Linköping University. This work was supported by grant from the Medical Research Council of Southeast Sweden (FORSS), by grant no. 20162075-5.1 from the Swedish Research Council (VR) and by faculty grants from the Linnaeus University.

\section{Compliance with ethical standards}

Conflict of interest The authors declare that they have no conflict of interest.

Ethical approval All procedures performed in studies involving human participants were in accordance with the ethical standards of the institutional and/or national research committee (approved by the Regional Ethical Review Board in Linköping, Sweden, reference number 2011/474-31) and with the 1964 Helsinki declaration and its later amendments or comparable ethical standards.

Informed consent Informed consent was obtained from all individual participants included in the study.

Open Access This article is licensed under a Creative Commons Attribution 4.0 International License, which permits use, sharing, adaptation, distribution and reproduction in any medium or format, as long as you give appropriate credit to the original author(s) and the source, provide a link to the Creative Commons licence, and indicate if changes were made. The images or other third party material in this article are included in the article's Creative Commons licence, unless indicated otherwise in a credit line to the material. If material is not included in the article's Creative Commons licence and your intended use is not permitted by statutory regulation or exceeds the permitted use, you will need to obtain permission directly from the copyright holder. To view a copy of this licence, visit http://creativecommons.org/licenses/by/4.0/.

\section{References}

1. Oosting M, Berende A, Sturm P, Ter Hofstede HJ, de Jong DJ, Kanneganti TD, van der Meer JW, Kullberg BJ, Netea MG, Joosten LA (2010) Recognition of Borrelia burgdorferi by NOD2 is central for the induction of an inflammatory reaction. J Infect Dis 201(12):1849-1858. https://doi.org/10.1086/652871

2. Skogman BH, Hellberg S, Ekerfelt C, Jenmalm MC, Forsberg P, Ludvigsson J, Bergstrom S, Ernerudh J (2012) Adaptive and innate immune responsiveness to Borrelia burgdorferi sensu lato in exposed asymptomatic children and children with previous clinical Lyme borreliosis. Clin Dev Immunol 2012:294587. https://doi. org $/ 10.1155 / 2012 / 294587$

3. Wilhelmsson P, Fryland L, Borjesson S, Nordgren J, Bergstrom S, Ernerudh J, Forsberg P, Lindgren PE (2010) Prevalence and diversity of Borrelia species in ticks that have bitten humans in Sweden. $\mathrm{J}$ Clin Microbiol 48(11):4169-4176. https://doi.org/10.1128/JCM. 01061-10

4. Wilhelmsson P, Fryland L, Lindblom P, Sjowall J, Ahlm C, Berglund J, Haglund M, Henningsson AJ, Nolskog P, Nordberg M, Nyberg C, Ornstein K, Nyman D, Ekerfelt C, Forsberg P, Lindgren PE (2016) A prospective study on the incidence of Borrelia burgdorferi sensu lato infection after a tick bite in 
Sweden and on the Aland Islands, Finland (2008-2009). Ticks Tick Borne Dis 7(1):71-79. https://doi.org/10.1016/j.ttbdis.2015.08.009

5. Rauter C, Hartung T (2005) Prevalence of Borrelia burgdorferi sensu lato genospecies in Ixodes ricinus ticks in Europe: a metaanalysis. Appl Environ Microbiol 71(11):7203-7216. https:// doi.org/10.1128/AEM.71.11.7203-7216.2005

6. Stanek G, Fingerle V, Hunfeld KP, Jaulhac B, Kaiser R, Krause A, Kristoferitsch W, O'Connell S, Ornstein K, Strle F, Gray J (2011) Lyme borreliosis: clinical case definitions for diagnosis and management in Europe. Clin Microbiol Infect 17(1):69-79. https://doi. org/10.1111/j.1469-0691.2010.03175.x

7. Strle F, Stanek G (2009) Clinical manifestations and diagnosis of Lyme borreliosis. Curr Probl Dermatol 37:51-110. https://doi.org/ $10.1159 / 000213070$

8. Piesman J, Gern L (2004) Lyme borreliosis in Europe and North America. Parasitology 129(Suppl):S191-S220

9. Fryland L, Wilhelmsson P, Lindgren PE, Nyman D, Ekerfelt C, Forsberg P (2011) Low risk of developing Borrelia burgdorferi infection in the south-east of Sweden after being bitten by a Borrelia burgdorferi-infected tick. Int J Infect Dis 15(3):e174e181. https://doi.org/10.1016/j.ijid.2010.10.006

10. Ekerfelt C, Masreliez C, Svenvik M, Ernerudh J, Roberg M, Forsberg P (2001) Antibodies and T-cell reactivity to Borrelia burgdorferi in an asymptomatic population: a study of healthy blood donors in an inland town district in the south-east of Sweden. Scand J Infect Dis 33(11):806-808

11. Fahrer H, van der Linden SM, Sauvain MJ, Gern L, Zhioua E, Aeschlimann A (1991) The prevalence and incidence of clinical and asymptomatic Lyme borreliosis in a population at risk. $\mathrm{J}$ Infect Dis 163(2):305-310

12. Gustafson R, Svenungsson B, Gardulf A, Stiernstedt G, Forsgren M (1990) Prevalence of tick-borne encephalitis and Lyme borreliosis in a defined Swedish population. Scand J Infect Dis 22(3):297-306

13. Steere AC, Franc S, Wormser GP, Hu LT, Branda JA, Hovius JWR, Li X, Mead PS (2017) Correction: Lyme borreliosis. Nat Rev Dis Primers 3:17062. https://doi.org/10.1038/nrdp.2017.62

14. Ekdahl KN, Persson B, Mohlin C, Sandholm K, Skattum L, Nilsson B (2018) Interpretation of serological complement biomarkers in disease. Front Immunol 9:2237. https://doi.org/10.3389/fimmu. 2018.02237

15. Sandholm K, Henningsson AJ, Save S, Bergstrom S, Forsberg P, Jonsson N, Ernerudh J, Ekdahl KN (2014) Early cytokine release in response to live Borrelia burgdorferi sensu lato spirochetes is largely complement independent. PLoS One 9(9):e108013. https://doi. org/10.1371/journal.pone. 0108013

16. Delves PJ, Roitt IM (2000) The immune system. First of two parts. N Engl J Med 343(1):37-49. https://doi.org/10.1056/ NEJM200007063430107

17. Oosting M, Buffen K, van der Meer JW, Netea MG, Joosten LA (2016) Innate immunity networks during infection with Borrelia burgdorferi. Crit Rev Microbiol 42(2):233-244. https://doi.org/10. 3109/1040841X.2014.929563

18. Kraiczy P (2016) Hide and seek: how Lyme disease spirochetes overcome complement attack. Front Immunol 7:385. https://doi. org/10.3389/fimmu.2016.00385

19. Ekdahl KN, Henningsson AJ, Sandholm K, Forsberg P, Ernerudh J, Ekerfelt C (2007) Immunity in borreliosis with special emphasis on the role of complement. Adv Exp Med Biol 598:198-213. https:// doi.org/10.1007/978-0-387-71767-8_14

20. Henningsson AJ, Ernerudh J, Sandholm K, Carlsson SA, Granlund H, Jansson C, Nyman D, Forsberg P, Nilsson Ekdahl K (2007) Complement activation in Lyme neuroborreliosis-increased levels of $\mathrm{C} 1 \mathrm{q}$ and $\mathrm{C} 3 \mathrm{a}$ in cerebrospinal fluid indicate complement activation in the CNS. J Neuroimmunol 183(1-2):200-207. https://doi.org/10.1016/j.jneuroim.2006.10.022

21. Carlsson H, Ekerfelt C, Henningsson AJ, Brudin L, Tjernberg I (2018) Subclinical Lyme borreliosis is common in south-eastern Sweden and may be distinguished from Lyme neuroborreliosis by sex, age and specific immune marker patterns. Ticks Tick Borne Dis. https://doi.org/10.1016/j.ttbdis.2018.02.011

22. Anonymous (2012) Instructions for use, GARXBB005EN, recomBead Borrelia IgM and IgG. Mikrogen GmbH, Neuried

23. Mygland A, Ljostad U, Fingerle V, Rupprecht T, Schmutzhard E, Steiner I, European Federation of Neurological S (2010) EFNS guidelines on the diagnosis and management of European Lyme neuroborreliosis. Eur J Neurol 17(1):8-16, e11-14. https://doi.org/ 10.1111/j.1468-1331.2009.02862.x

24. Bexborn F, Engberg AE, Sandholm K, Mollnes TE, Hong J, Nilsson Ekdahl K (2009) Hirudin versus heparin for use in whole blood in vitro biocompatibility models. J Biomed Mater Res A 89(4):951-959. https://doi.org/10.1002/jbm.a.32034

25. Asbrink E, Hovmark A, Hederstedt B (1984) The spirochetal etiology of acrodermatitis chronica atrophicans Herxheimer. Acta Derm Venereol 64(6):506-512

26. Ornstein K, Berglund J, Nilsson I, Norrby R, Bergstrom S (2001) Characterization of Lyme borreliosis isolates from patients with erythema migrans and neuroborreliosis in southern Sweden. J Clin Microbiol 39(4):1294-1298. https://doi.org/10.1128/JCM.39. 4.1294-1298.2001

27. Nilsson Ekdahl K, Nilsson B, Pekna M, Nilsson UR (1992) Generation of $\mathrm{iC} 3$ at the interface between blood and gas. Scand J Immunol 35(1):85-91

28. Mollnes TE, Lea T, Froland SS, Harboe M (1985) Quantification of the terminal complement complex in human plasma by an enzymelinked immunosorbent assay based on monoclonal antibodies against a neoantigen of the complex. Scand J Immunol 22(2): 197-202

29. Blaabjerg OBM, Gry H et al (1993) Faelles Referenceintervaller i Norden for 9 Plasmaproteiner. Klinisk kemi i Norden 5(4):13-17

30. Bennet L, Fraenkel CJ, Garpmo U, Halling A, Ingman M, Ornstein K, Stjernberg L, Berglund J (2006) Clinical appearance of erythema migrans caused by Borrelia afzelii and Borrelia garinii-effect of the patient's sex. Wien Klin Wochenschr 118(17-18):531-537. https:// doi.org/10.1007/s00508-006-0659-1

31. Johansson M, Manfredsson L, Wistedt A, Serrander L, Tjernberg I (2017) Significant variations in the seroprevalence of C6 ELISA antibodies in a highly endemic area for Lyme borreliosis: evaluation of age, sex and seasonal differences. APMIS 125(5):476-481. https://doi.org/10.1111/apm.12664

32. Giefing-Kroll C, Berger P, Lepperdinger G, Grubeck-Loebenstein B (2015) How sex and age affect immune responses, susceptibility to infections, and response to vaccination. Aging Cell 14(3):309 321. https://doi.org/10.1111/acel.12326

33. Gaya da Costa M, Poppelaars F, van Kooten C, Mollnes TE, Tedesco F, Wurzner R, Trouw LA, Truedsson L, Daha MR, Roos A, Seelen MA (2018) Age and sex-associated changes of complement activity and complement levels in a healthy caucasian population. Front Immunol 9:2664. https://doi.org/10.3389/fimmu. 2018.02664

34. Tjernberg I, Kruger G, Eliasson I (2007) C6 peptide ELISA test in the serodiagnosis of Lyme borreliosis in Sweden. Eur J Clin Microbiol Infect Dis 26(1):37-42. https://doi.org/10.1007/s10096006-0239-3

Publisher's note Springer Nature remains neutral with regard to jurisdictional claims in published maps and institutional affiliations. 